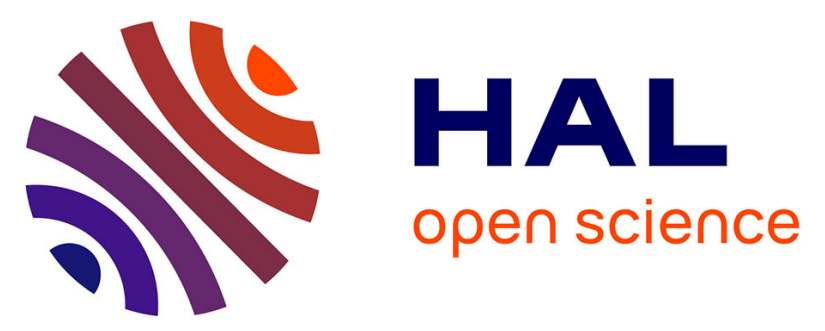

\title{
Variation in genes coding for AMP-activated protein kinase (AMPK) and breast cancer risk in the European Prospective Investigation on Cancer (EPIC)
}

Daniele Campa, Rainer Claus, Lucie Dostal, Angelika Stein, Jenny Chang-Claude, Karina Meidtner, Heiner Boeing, Anja Olsen, Anne

Tjønneland, Kim Overvad, et al.

\section{To cite this version:}

Daniele Campa, Rainer Claus, Lucie Dostal, Angelika Stein, Jenny Chang-Claude, et al.. Variation in genes coding for AMP-activated protein kinase (AMPK) and breast cancer risk in the European Prospective Investigation on Cancer (EPIC). Breast Cancer Research and Treatment, 2010, 127 (3), pp.761-767. 10.1007/s10549-010-1269-1 . hal-00615389

\section{HAL Id: hal-00615389 \\ https://hal.science/hal-00615389}

Submitted on 19 Aug 2011

HAL is a multi-disciplinary open access archive for the deposit and dissemination of scientific research documents, whether they are published or not. The documents may come from teaching and research institutions in France or abroad, or from public or private research centers.
L'archive ouverte pluridisciplinaire HAL, est destinée au dépôt et à la diffusion de documents scientifiques de niveau recherche, publiés ou non, émanant des établissements d'enseignement et de recherche français ou étrangers, des laboratoires publics ou privés. 


\section{Variation in genes coding for AMP-activated protein kinase (AMPK) and breast cancer risk in the European Prospective Investigation on Cancer (EPIC)}

Daniele Campa ${ }^{1}$, Rainer Claus $^{1}$, Lucie Dostal ${ }^{1}$, Angelika Stein ${ }^{1}$ Jenny Chang-Claude ${ }^{1}$, Karina Meidtner ${ }^{2}$, Heiner Boeing ${ }^{2}$, Anja Olsen ${ }^{3}$, Anne Tjønneland ${ }^{3}$, Kim Overvad ${ }^{4,5}$, Laudina Rodríguez ${ }^{6}$, Catalina Bonet ${ }^{7}$, MariaJosé Sánchez ${ }^{8,9}$, Pilar Amiano ${ }^{9,10}$, José María Huerta9,11, Aurelio Barricarte ${ }^{9,12}$, Kay-Tee Khaw ${ }^{13}$, Nicholas Wareham ${ }^{14}$, Ruth C. Travis ${ }^{15}$, Naomi E. Allen ${ }^{15}$, Antonia Trichopoulou ${ }^{16,17}$, Christina Bamia ${ }^{17}$ Vassiliki Benetou $^{17}$, Domenico Palli ${ }^{18}$, Claudia Agnoli ${ }^{19}$, Salvatore Panico ${ }^{20}$, Rosario Tumino ${ }^{21}$, Carlotta Sacerdote ${ }^{22,23}$, Henk van Kranen ${ }^{24}$, H. Bas Bueno-deMesquita $^{24}$, Petra HM Peeters ${ }^{25}$, Carla H van Gils ${ }^{25}$, Per Lenner ${ }^{26}$, Malin Sund $^{27}$, Eiliv Lund ${ }^{28}$, Inger Torhild Gram ${ }^{28}$, Sabina Rinaldi ${ }^{29}$, Veronique Chajes ${ }^{29}$, Isabelle Romieu ${ }^{29}$, Pierre Engel ${ }^{30}$, Marie Christine BoutronRuault $^{30}$, Françoise Clavel-Chapelon ${ }^{30}$, Afshan Siddiq ${ }^{31}$, Elio Riboli ${ }^{31}$, Federico Canzian ${ }^{1}$ and Rudolf Kaaks ${ }^{1}$

1 German Cancer Research Center (DKFZ), Heidelberg, Germany

2 Department of Epidemiology, Deutsches Institut für Ernährungsforschung, Potsdam-Rehbrücke, Germany

3 The Danish Cancer Society, Institute of Cancer Epidemiology, Copenhagen, Denmark

4 Department of Cardiology, Center for Cardiovascular Research, Aalborg Hospital, Aarhus University Hospital, Aalborg, Denmark

5 Department of Epidemiology, School of Public Health, Aarhus University, Denmark

6 Public Health and Participation Directorate, Health and Health Care Services Council, Asturias, Spain

7 Department of Epidemiology, Catalan Institute of Oncology, Barcelona (Spain)

8 Andalusian School of Public Health, Granada, Spain

9 Consortium for Biomedical Research in Epidemiology and Public Health (CIBERESP), Spain

10 Public Health Division of Gipuzkoa, Instituto Investigación BioDonostia, IISBioDonostia, Gipuzkoa; 
${ }^{11}$ Department of Epidemiology, Murcia Regional Health Authority, Murcia, Spain

${ }^{12}$ Navarre Public Health Institute, Pamplona, Spain

${ }^{13}$ University of Cambridge School of Clinical Medicine, Cambridge, UK

${ }^{14}$ MRC Epidemiology Unit, Cambridge, UK

${ }^{15}$ Cancer Epidemiology Unit, Nuffield Department of Clinical Medicine, University of Oxford, Oxford, United Kingdom

${ }^{16}$ Hellenic Health Foundation, Athens, Greece

${ }^{17}$ WHO Collaborating Center for Food and Nutrition Policies, Department of Hygiene, Epidemiology and Medical Statistics, University of Athens Medical School, Athens, Greece

${ }^{18}$ Molecular and Nutritional Epidemiology Unit, Cancer Research and Prevention Institute - ISPO, Florence, Italy

${ }^{19}$ Fondazione IRCCS Istituto Nazionale dei Tumori, Milan, Italy 20 Institution, Town, Country

20 Department of Clinical and Experimental Medicine Federico II University, Naples, Italy

${ }^{21}$ Cancer registry and histopathology unit, "Civile - M.P.Arezzo" hospital, ASP 7, Ragusa, Italy

${ }^{22}$ Center for Cancer Prevention (CPO-Piemonte), Turin, Italy

${ }^{23}$ Human Genetic Foundation (HuGeF), Turin, Italy

${ }^{24}$ Centre for Nutrition and Health (CVG), National Institute for Public Health and the Environment, Bilthoven, Netherlands

25 Julius Center, University Medical Center, Utrecht, The Netherlands

${ }^{26}$ Dept of Public Health and Clinical Medicine, Umeå University, Umeå, Sweden

27 Dept of Surgery, Umeå University, Umeå, Sweden

${ }^{28}$ Institute of Community Medicine University of Troms $\emptyset$, Troms $\varnothing$, Norway

${ }^{29}$ International Agency for Research on Cancer, Lyon, France

30 INSERM UMR 1018, Team 9: Nutrition, Hormones et Santé des femmes, Centre de Recherche en Epidémiologie et Santé des Populations, Hôpital Paul Brousse, Villejuif, France

${ }^{31}$ Imperial College, London, UK

Short title: AMPK SNPs and breast cancer risk

Keywords: AMP-activated protein kinase, breast cancer, cancer susceptibility, body-mass index

Corresponding author: Rudolf Kaaks

Department of Cancer Epidemiology 
German Cancer Research Center

Im Neuenheimer Feld 280

69120 Heidelberg

Germany

Tel. +49-6221-422219

Fax +49-6221-422203

E-mail r.kaaks@dkfz.de 


\section{Abstract}

Purpose AMP-activated protein kinase (AMPK) is an energysensing/signalling intracellular protein which is activated by an increase in the cellular AMP:ATP ratio after ATP depletion. Once activated, AMPK inhibits fatty acid synthesis and the Akt-mTOR pathway, and activates the p53-p21 axis. All these molecular mechanisms are thought to play a key role in breast carcinogenesis We investigated the genetic variability of four genes encoding AMPK (PRKAA1, PRKAA2, PRKAB1 and PRKAB2).

Methods Using a tagging approach and selecting SNPs we covered all the common genetic variation of these genes. We tested association of tagging SNPs in our four candidate genes with breast cancer (BC) risk in a study of 1340 BC cases and 2536 controls nested into the European Prospective Investigation into Cancer and Nutrition (EPIC). Given the relevance of AMPK on fatty acid synthesis and the importance of body fatness as a BC risk factor, we tested association of SNPs and body-mass index as well.

Results and conclusion We observed no statistically significant association between the SNPs in the PRKAs genes and BC risk and BMI after correction for multiple testing. 


\section{Introduction}

Hormonal and metabolic factors have been postulated to mediate the effects of a western nutritional lifestyle which is characterized by low rates of energy expenditure and a high-energy diet, rich in saturated fats, refined carbohydrates and animal protein on breast cancer risk [1-5]. One of the metabolic key players is AMP-activated protein kinase (AMPK), a heterotrimeric complex comprising one alpha catalytic subunit and noncatalytic (regulatory) beta and gamma subunits [6].

Known as the "fuel sensor of the cell", AMPK is an energysensing/signalling intracellular protein which is inactive unless it has been phosphorylated in response to cellular stresses that deplete cellular energy levels and increase the AMP/ATP ratio [7-9]. Once activated, AMPK switches on ATP-generating (catabolic) pathways and switches off ATPconsuming (anabolic) pathways, allowing the cell to restore its energy balance [7]. The unique ability of AMPK to directly sense cellular energy places it in an ideal position to ensure that cell division, which is a highly energy-consuming process, only proceeds if cells have sufficient metabolic resources to support cell proliferation [10].

AMPK activation overcomes the growth-stimulatory signalling via multiple mechanisms. First, AMPK activity inhibits fatty acid and cholesterol biosynthesis and promotes fatty acid oxidation, thereby opposing intracellular lipid accumulation and development of insulin resistance in non-adipose tissues [11]. Numerous studies have investigated the role of fatty acids, dietary fat, and obesity in cancer 
development $[12,4,2,13-22]$. Second, AMPK inhibits mTOR signaling downstream of Akt, and inhibition of mTOR pathway has been reported to inhibit tumour growth in vitro and metastasis in experimental animals $[23,24]$. This makes AMPK activation a possible therapeutic target for cancers with activated Akt signaling pathway [25].

Finally, Igata and coworkers reported that AMPK activation results in cell cycle arrest at the $\mathrm{G} 1$ phase and inhibited cell proliferation via activation of the p53-p21 axis [26-28].

The above observations led us to hypothesize that AMPK may be centrally implicated in mammary gland carcinogenesis, and that polymorphic alleles of its encoding genes that modify its expression or activity confer altered BC susceptibility. In this report we investigated for the first time, the genetic variability of the genes encoding PRKAA1, $P R K A A 2, P R K A B 1$ and $P R K A B 2$. By using a tagging approach and selecting SNPs we covered all the common genetic variation of these genes. We have tested association of tagging SNPs in our four candidate genes with BC risk in a study of 1340 BC cases and 2536 controls nested into the European Prospective Investigation into Cancer and Nutrition (EPIC). Given the key role of AMPK in energy sensing and inhibition of fatty acid synthesis, we tested also association of SNPs with body-mass index (BMI). 


\section{Materials and Methods}

\section{The EPIC cohort}

A fully detailed description of EPIC has been published elsewhere [29]. Briefly, the EPIC cohort consists of about 370,000 women and 150,000 men, aged 35-69, recruited between 1992 and 2005 in 10 Western European countries. Follow-up for cancer incidence was last performed in 2007.

The vast majority (>97\%) of subjects recruited in the EPIC cohort are of European ('Caucasian') origin. All EPIC study subjects provided anthropometric measurements (height, weight, and waist and hip circumferences) and extensive, standardized questionnaire information about medical history, diet, physical activity, smoking, and other lifestyle factors. Women also answered questions about menstrual and reproductive history, hysterectomy, ovariectomy, and use of exogenous hormones for contraception or treatment of menopausal symptoms. About 260,000 women and 140,000 men provided a blood sample. Follow-up for cancer incidence was last performed in 2007.

Cases of cancer occurring after recruitment into the cohort and blood donation are identified through local and national cancer registries in 7 of the 10 countries, and in France, Germany, and Greece by a combination of contacts with national health insurances and/or active follow-up through the study subjects or their next of kin. Follow-up on vital status is achieved through record linkage with mortality registries. 


\section{Selection of case and control subjects}

Case subjects were selected among women who developed BC after blood collection. Control subjects (1-2 controls per case) were selected randomly by incidence density sampling, matching the cases for centre of recruitment, age at blood donation, duration of follow-up, menopausal status at the time of blood donation and use of exogenous hormones. This study did not include women who were using hormone replacement therapy at the time of blood donation. A total of 1340 invasive BC cases and 2536 controls were included in the present study. Each control was free of cancer up to the duration of follow up of the index case. The study was approved by the ethical review boards of the International Agency for Research on Cancer, and of the collaborating institutions responsible for subject recruitment in each of the EPIC recruitment centres.

\section{Selection of tagging SNPS}

We aimed at surveying the entire set of common genetic variants in the PRKAA1, PRKAA2, PRKAB1 and PRKAB2 genes.

We followed a SNP-tagging approach [30]. Gene regions were defined as the sequence between $5 \mathrm{~kb} 5^{\prime}$ of the beginning of the first known exon and $5 \mathrm{~kb} 3^{\prime}$ of the end of the last known exon. We included all polymorphisms in each gene region with minor allele frequency (MAF) $\geq 5 \%$ in Caucasians from the International HapMap Project (version 22; http://www.hapmap.org). 
Tagging SNPs were selected with the use of the Tagger program within Haploview (http://www.broad.mit.edu/mpg/haploview/; http://www.broad.mit.edu/mpg/tagger/; [31]), using pairwise tagging with a minimum $r^{2}$ of 0.8 . We used genotypes downloaded from the HapMap database as input for Tagger.

\section{DNA extraction and genotyping}

DNA was extracted from blood samples on an Autopure instrument (Qiagen, Hilden, Germany) with Puregene chemistry (Qiagen, Hilden, Germany). The order of DNAs from cases and controls was randomized on PCR plates in order to ensure that an equal number of cases and controls could be analyzed simultaneously.

26 SNPs were genotyped with the iPLEX Gold application (Sequenom, San Diego, USA), based on multiplexed PCR amplification of short amplimers surrounding the SNPs, single nucleotide primer extension reaction and separation of extension products by matrix-assisted laser desorption/ionization-time of flight (MALDI-TOF)[32], according to the manufacturer instructions.Plates were read on MassARRAY ${ }^{\circledR}$ system using the Typer software version 4.0 from Sequenom (San Diego, CA). The remaining 15 SNPs were performed using the Taqman assay. Predesigned assays were purchased from Applied Biosystems (Foster City, CA). Genotyping was performed according to manufacturer's specifications, and PCR plates were read on an ABI PRISM 7900HT instrument using SDS software version 2.4 (Applied Biosystems). 
Any sample where greater than $25 \%$ of the SNPs failed had all of the SNPs set to missing and these subjects were dropped from analysis. We then filtered data to remove poorly performing SNPs: all SNPs that failed on $25 \%$ of samples or more were set to missing, as were all SNPs that showed statistically significant $\left(p<10^{-3}\right)$ deviations from Hardy-Weinberg equilibrium (HWE) among controls.

Repeated quality control genotypes ( $8 \%$ of the total) showed an average concordance of $99.50 \%$.

All genotyping was performed at the German Cancer Research Center (DKFZ). Since the genotyping was performed using two different techniques one of the SNPs (rs10074991) was typed on all subjects using both TaqMan and iPlex to ensure an internal quality control; concordance rate was $100 \%$.

\section{Statistical analysis}

The frequency distribution of genotypes was examined for cases and controls. We used conditional logistic regression for multivariate analyses to assess the main effects of the genetic polymorphism on BC risk assuming dominant, recessive and codominant models of inheritance. The most common allele in the controls was held as the reference category in calculating the odds ratio (OR). Cases with carcinomas in situ ( $\mathrm{n}=84$ cases and 148 matched controls) were excluded from these analyses. Subgroup analyses were performed based on menopausal status, age (with cutpoint at 50 or 55 years of age at diagnosis) and BMI (subjects 
with $\mathrm{BMI} \geq 30$ were categorized as obese, $25 \leq \mathrm{BMI}<30$ as overweight and $<25$ as normal weight). Additional analyses were performed by including cases of carcinoma in situ, by excluding cases diagnosed shortly (6 months, 1 year or 2 years) after blood drawing. Relationships of polymorphic gene variants with BMI were estimated by standard regression models and percentage of difference in geometric means in each genotype category compared to the major homozygote category was calculated. An additional analysis was performed by calculating odds ratios for obese or overweight vs. normal weight with unconditional logistic regression. All BMI analyses were adjusted for age at blood donation, center of recruitment and $\mathrm{BC}$ case-control status.

Polymorphisms selected as tagging SNPs had a very high coverage of the total linkage disequilibrium of the gene region (on average $r^{2}=0.943$ for the PRKAA1 gene, $r^{2}=0.907$ for PRKAA2, $r^{2}=0.959$ for PRKAB1 and $r^{2}=0.988$ for $P R K A B 2$ ), therefore we assumed that haplotypes were adequately captured by our tagging SNPs, and we did not attempt a haplotype analysis. In this study we tested SNPs using a study-wise statistically significant threshold of $0.05 / 39=0.0013$. Thus $p$-values will be interpreted in light of the multiple comparisons.

STrengthening the REporting of GeneticAssociation studies (STREGA) criteria were used to report the data.[33] 


\section{Results}

This study explored the association between 41 DNA polymorphisms in four key genes encoding AMPK and BC risk, as well as with BMI.

A total of 3876 women, 1340 BC cases and 2536 matched controls were included in the analysis. Table 1 summarizes the baseline characteristics of cases and controls. The genotype distributions at all SNPs typed in the EPIC samples were in Hardy-Weinberg equilibrium in controls, with non-significant $\chi^{2}$ values with the exception of rs3805486 (PRKAA1) and rs11584787 (PRKAB2) which were excluded from further analysis. The average call rate was $92 \%(80 \%-100 \%)$.

The frequencies and distribution of the genotypes and the odds ratios for the association of each polymorphism with BC risk and BMI level are described in Supplementary table 1 and in Supplementary table 2 respectively. In table 2 and 3 we show for each gene the SNP with the most significant association respectively for BC risk and BMI. The strongest association we observed was for the heterozygous carriers ( $C / T)$ of the SNP rs17159882, of the PRKAB2 gene, which was associated with an increased risk of $B C: O R=1.50(95 \%$ CI 1.11-2.02) $P=0.009$. Since the MAF of this polymorphism is 0.056 the homozygous carriers were too few ( 1 case; 3 controls) to meaningfully test the possible association between this genotype and risk.

No other statistically significant association was observed between the remaining SNPs in the PRKAs genes and BC risk overall and stratifying for age or BMI. We also performed analysis dividing the subjects according to 
their menopausal status, although the number of pre-menopausal women was fairly small (323 cases 723 controls). We did not find any significant association between any of the polymorphisms and $B C$ in the strata considered.

Additional analyses performed by including cases of carcinoma in situ, excluding cases diagnosed shortly after blood drawing or dividing in subgroups for menopausal status showed essentially the same results as using all cases and controls (data not shown). 


\section{Discussion}

We postulated that genetic polymorphisms in PRKAA1, PRKAA2, $P R K A B 1$ and $P R K A B 2$ might play an important role in development of $\mathrm{BC}$ given their key function in the regulation of whole-body energy metabolism and the response to acute changes in energy levels in individual cells. AMPK activity inhibits fatty acid and cholesterol biosynthesis and promotes fatty acid oxidation, thereby opposing intracellular lipid accumulation and development of insulin resistance in non-adipose tissues. It overcomes the growth-stimulatory signalling also by inhibiting the mTOR pathway and activating the p53-p21 axis $[34,35,25]$.

Moreover, recent discoveries that a tumour suppresor, LKB1, is present upstream and two distinct tumour suppressors, p55 and TSC2 lie downstream, have provided novel evidence that AMPK may function as a suppressor of cell proliferation [25].

Recently metformin (an AMPK activator) which is increasingly being considered and tested for treatment of breast cancer; has been shown to reduce aromatase expression in breast adipose stromal cells, suggesting that AMPK activation could also reduce breast cancer risk by downregulating local estrogen production $[36,37]$.

We tested in a large-scale association study, nested within the EPIC cohort, the involvement in $\mathrm{BC}$ risk of common polymorphisms of the four genes. We did not observe any significant association between any polymorphisms in the PRKAs genes and an increased risk of cancer with 
the exception of one SNP, rs17159882, which belongs to the PRKAB2 gene locus. This SNP is situated at $1620 \mathrm{bp} 5^{\prime}$ of the gene. So one can postulate that the polymorphism might lie in the gene promoter impairing its function and thus increasing the risk of BC. However, since we tested 39 SNPs a rigorous study-wise statistically significant threshold is $0.05 / 39=0.0013$. Thus after correction for multiple testing, this finding is not significant. One likely explanation might be chance finding.

Body fatness directly affects levels of many circulating hormones, such as insulin, insulin-like growth factors, oestrogens and inflammatory factors, which are all well known risk factors for BC risk $[36,18,19,38-40]$, thus creating an environment that encourages carcinogenesis and discourages apoptosis. For these reason we performed also a regression analysis to investigate the possible impact of PRKA gene polymorphic variants on BMI. We have not found any statistically significant association with BMI. In this study we had sufficient power $(0.80$ for codominant model) to detect $O R=1.25$ at alpha $=1.2 \times 10^{-3}$ (study-wide significance $p$ threshold) for a SNP with a MAF of 0.30 , or to detect $\mathrm{OR}=1.40$ for a SNP with a MAF of 0.10 at the same level of alpha.

In conclusion, we have exhaustively investigated the complete genetic variation in PRKAA1, PRKAA2, PRKAB1 and PRKAB2 in relation with BMI and BC risk, in a large study of almost 4000 women. We did not find any SNP that emerged at the study-wise level of $p<0.0013$ and thus we can confidently exclude a major role of these SNPs in BMI alteration and in BC risk. 


\section{Competing interests}

The authors declare that they have no competing interests 


\section{Acknowledgements}

Specific results of this study were obtained with financial support from the US Army Medical Research and Material Command (W81XWH-04-10271).

The EPIC study was funded by "Europe Against Cancer" Programme of the European Commission (SANCO); Ligue contre le Cancer, Institut Gustave Roussy, Mutuelle Générale de l'Education Nationale, Institut National de la Santé et de la Recherche Médicale (INSERM); German Cancer Aid; German Cancer Research Center; German Federal Ministry of Education and Research; Danish Cancer Society; Health Research Fund (FIS) of the Spanish Ministry of Health; the participating regional governments and institutions of Spain; Cancer Research UK; Medical Research Council, UK; Hellenic Ministry of Health and Social Solidarity; the Stavros Niarchos Foundation and the Hellenic Health Foundation; Italian Association for Research on Cancer; Italian National Research Council; Dutch Ministry of Public Health, Welfare and Sports (VWS), Dutch Ministry of Health, Netherlands Cancer Registry (NKR), LK Research Funds, Dutch Prevention Funds, Dutch ZON (Zorg Onderzoek Nederland), World Cancer Research Fund (WCRF) (The Netherlands); Statistics Netherlands; Swedish Cancer Society; Swedish Scientific Council; Regional Government of Skane, Sweden; Norwegian Cancer Society. 


\section{Supplementary material}

Supplementary table 1. Main effects of 39 SNPs genotyped in the study on breast cancer risk. Columns in this table show: gene name; NCBI dbSNP rs number; the three possible genotypes; numbers of cases for each of the three genotypes; controls for each of the three genotypes; odds ratios for heterozygotes and odds ratios for homozygotes for the rare allele with $95 \%$ confidence interval (referred to the homozygotes for the common allele); associated p-value; p-value of the trend test.

Supplementary table 2. Main effects of 39 SNPs genotyped in the study on BMI. Columns in this table show: gene name; NCBI dbSNP rs number; possible genotypes; numbers of subjects for each of the three genotypes; BMI mean for each of the three genotypes with $95 \%$ confidence interval; p-value of the trend test. 
Table 1. Baseline characteristics of $B C$ cases and control subjects.

\begin{tabular}{lcc}
\hline Variable & Cases & Controls \\
\hline Number & $1340^{\mathrm{a}}$ & $2536^{\mathrm{a}}$ \\
Women with carcinoma in situ & $84^{\mathrm{a}}$ & $148^{\mathrm{a}}$ \\
Pre-menopausal women & $323^{\mathrm{a}}$ & $723^{\mathrm{a}}$ \\
Peri-menopausal women & $116^{\mathrm{a}}$ & $211^{\mathrm{a}}$ \\
Post-menopausal women & $901^{\mathrm{a}}$ & $1602^{\mathrm{a}}$ \\
Mean age at blood donation & $55.49(40.6-67.5)^{\mathrm{b}}$ & $55.0(40.1-67.9)^{\mathrm{b}}$ \\
Mean age at diagnosis & $57.8(44.0-70.0)^{\mathrm{b}}$ & - \\
Height & $161.8(151.0-172.0)^{\mathrm{b}}$ & $160.7(150.0-172.0)^{\mathrm{b}}$ \\
Weight & $67.5(51.8-89.0)^{\mathrm{b}}$ & $67.2(51.0-89.4)^{\mathrm{b}}$ \\
Body mass index & $25.8(20.2-34.3)^{\mathrm{b}}$ & $26.0(20.1-34.9)^{\mathrm{b}}$ \\
\hline
\end{tabular}

${ }^{a}$ Number of subjects

${ }^{\mathrm{b}}$ Mean (5th - 95th percentiles) 
Table 2. Associations between SNPs in candidate genes and breast cancer risk. For each gene, the SNP with the lowest $p$-value is reported.

\begin{tabular}{|c|c|c|c|c|c|c|c|c|c|c|c|}
\hline \multirow[t]{2}{*}{ Gene } & \multirow{2}{*}{$\begin{array}{l}\text { tagSNP } \\
\text { rs_number }\end{array}$} & \multirow[t]{2}{*}{ Chr } & \multirow[t]{2}{*}{ Position } & \multicolumn{3}{|c|}{ Cases/Controls } & \multirow{2}{*}{$\begin{array}{r}\text { OR Mm vs MM } \\
(95 \% C I)^{b}\end{array}$} & \multirow[t]{2}{*}{$P_{\text {value }}$} & \multirow{2}{*}{$\begin{array}{r}\text { OR mm vs MM } \\
(95 \% C I)^{b}\end{array}$} & \multirow[t]{2}{*}{$P_{\text {value }}$} & \multirow[t]{2}{*}{$p_{\text {trend }}$} \\
\hline & & & & $M / M^{c}$ & $M / m^{c}$ & $m / m^{c}$ & & & & & \\
\hline PRKAA1 & rs10053664 & 5 & $40,821,568$ & $392 / 680$ & $579 / 858$ & $219 / 321$ & $1.13(0.96-1.33)$ & 0.146 & $1.12(0.90-1.40)$ & 0.293 & 0.197 \\
\hline PRKAA2 & rs2796516 & 1 & $56,903,911$ & $866 / 1386$ & $297 / 438$ & $24 / 31$ & $1.11(0.93-1.32)$ & 0.247 & $0.81(0.43-1.51)$ & 0.629 & 0.228 \\
\hline PRKAB1 & rs4767830 & 12 & $118,519,607$ & $397 / 557$ & $568 / 894$ & $211 / 378$ & $0.90(0.76-1.06)$ & 0.216 & $0.81(0.66-1.00)$ & 0.055 & 0.051 \\
\hline PRKAB2 & rs17159882 & 1 & $145,091,689$ & $1099 / 1756$ & $90 / 99$ & $1 / 3$ & $1.50(1.11-2.02)$ & 0.009 & $0.56(0.06-5.69)$ & 0.621 & 0.017 \\
\hline
\end{tabular}

${ }^{a}$ Numbers may not add up to $100 \%$ of subjects due to genotyping failure.

${ }^{b}$ OR: odds ratio: estimated by conditional logistic regression with matching of cases and controls for age at blood donation and centre of recruitment; CI: confidence interval

${ }^{c} M / M$ : Homozygous for the major allele; $M / m$ : Heterozygous individuals; $m / m$ : Homozygous for the minor allele 
Table 3. Associations between BMI and SNPs belonging to candidate genes. For each gene, the SNP with the lowest p-value is reported.

\begin{tabular}{|c|c|c|c|c|c|c|c|c|}
\hline \multirow[t]{2}{*}{ Gene name } & \multirow[t]{2}{*}{ rs\# } & \multicolumn{2}{|c|}{ Homozygotes common allele } & \multicolumn{2}{|r|}{ Heterozygotes } & \multicolumn{2}{|c|}{ Homozygotes rare allele } & \multirow[t]{2}{*}{$P_{\text {trend }}$} \\
\hline & & $\mathbf{N}^{a}$ & BMI (95\%CI) & $\mathbf{N}$ & BMI (95\%CI) & $\mathbf{N}$ & BMI (95\%CI) & \\
\hline PRKAA1 & rs10074991 & 2039 & $25.86(25.66-26.05)$ & 1517 & $25.99(25.76-26.23)$ & 308 & $26.14(25.64-26.64)$ & 0.2131 \\
\hline PRKAA2 & rs2796516 & 2854 & $25.98(25.81-26.15)$ & 922 & $25.83(25.54-26.12)$ & 72 & $25.56(24.52-26.59)$ & 0.2591 \\
\hline$P R K A B 1$ & rs1541345 & 3477 & $25.90(25.74-26.06)$ & 393 & $26.17(25.73-26.61)$ & 4 & $28.29(23.91-32.68)$ & 0.1881 \\
\hline PRKAB2 & rs2304893 & 3141 & $25.87(25.71-26.04)$ & 549 & $26.18(25.80-26.56)$ & 22 & $27.43(25.55-29.30)$ & 0.0510 \\
\hline
\end{tabular}

${ }^{\text {a }}$ Numbers may not add up to $100 \%$ of subjects due to genotyping failure 


\section{References}

1. Augustin LS, Dal Maso L, La Vecchia C, Parpinel M, Negri E, Vaccarella S, Kendall CW, Jenkins DJ, Francesch S (2001) Dietary glycemic index and glycemic load, and breast cancer risk: a case-control study. Ann Oncol 12 (11):1533-1538

2. Bianchini F, Kaaks R, Vainio H (2002) Overweight, obesity, and cancer risk. Lancet Oncol 3 (9):565-574. doi:S1470204502008495 [pii]

3. Kaaks R (1996) Nutrition, hormones, and breast cancer: is insulin the missing link? Cancer Causes Control 7 (6):605-625

4. Kaaks R, Lukanova A (2001) Energy balance and cancer: the role of insulin and insulin-

like growth factor-I. Proc Nutr Soc 60 (1):91-106. doi:S002966510100012X [pii]

5. Muti P, Quattrin T, Grant BJ, Krogh V, Micheli A, Schunemann HJ, Ram M, Freudenheim JL, Sieri S, Trevisan M, Berrino F (2002) Fasting glucose is a risk factor for breast cancer: a prospective study. Cancer Epidemiol Biomarkers Prev 11 (11):1361-1368

6. Kemp BE, Stapleton D, Campbell DJ, Chen ZP, Murthy S, Walter M, Gupta A, Adams JJ, Katsis F, van Denderen B, Jennings IG, Iseli T, Michell BJ, Witters LA (2003) AMPactivated protein kinase, super metabolic regulator. Biochemical Society transactions $31(\mathrm{Pt}$ 1):162-168

7. Carling D (2005) AMP-activated protein kinase: balancing the scales. Biochimie 87 (1):8791

8. Hardie DG (2007) AMP-activated/SNF1 protein kinases: conserved guardians of cellular energy. Nat Rev Mol Cell Biol 8 (10):774-785

9. Hardie DG, Scott JW, Pan DA, Hudson ER (2003) Management of cellular energy by the AMP-activated protein kinase system. FEBS letters 546 (1):113-120

10. Towler MC, Hardie DG (2007) AMP-activated protein kinase in metabolic control and insulin signaling. Circulation research 100 (3):328-341

11. Hardie DG (1992) Regulation of fatty acid and cholesterol metabolism by the AMPactivated protein kinase. Biochimica et biophysica acta 1123 (3):231-238

12. Campa D, McKay J, Sinilnikova O, Husing A, Vogel U, Hansen RD, Overvad K, Witt PM, Clavel-Chapelon F, Boutron-Ruault MC, Chajes V, Rohrmann S, Chang-Claude J, Boeing H, Fisher E, Trichopoulou A, Trichopoulos D, Palli D, Villarini A, Sacerdote C, Mattiello A, Tumino R, Peeters PH, van Gils CH, Bas Bueno-de-Mesquita H, Lund E, Chirlaque MD, Sala N, Suarez LR, Barricarte A, Dorronsoro M, Sanchez MJ, Lenner P, Hallmans G, Tsilidis K, Bingham S, Khaw KT, Gallo V, Norat T, Riboli E, Rinaldi S, Lenoir G, Tavtigian SV, Canzian F, Kaaks R (2009) Genetic variation in genes of the fatty acid synthesis pathway and breast cancer risk. Breast cancer research and treatment 13. Menendez JA, Lupu R (2007) Fatty acid synthase and the lipogenic phenotype in cancer pathogenesis. Nat Rev Cancer 7 (10):763-777. doi:nrc2222 [pii]

$10.1038 / \mathrm{nrc} 2222$

14. Menendez JA, Colomer R, Lupu R (2005) Why does tumor-associated fatty acid synthase (oncogenic antigen-519) ignore dietary fatty acids? Med Hypotheses 64 (2):342-349.

doi:S0306-9877(04)00455-4 [pii]

10.1016/j.mehy.2004.07.022

15. Rossi S, Ou W, Tang D, Bhattacharya N, Dei Tos AP, Fletcher JA, Loda M (2006)

Gastrointestinal stromal tumours overexpress fatty acid synthase. The Journal of pathology 209 (3):369-375

16. Takahiro T, Shinichi K, Toshimitsu S (2003) Expression of fatty acid synthase as a prognostic indicator in soft tissue sarcomas. Clin Cancer Res 9 (6):2204-2212 
17. Yang YA, Morin PJ, Han WF, Chen T, Bornman DM, Gabrielson EW, Pizer ES (2003)

Regulation of fatty acid synthase expression in breast cancer by sterol regulatory element binding protein-1c. Exp Cell Res 282 (2):132-137. doi:S001448270200023X [pii]

18. Cleary MP, Grossmann ME (2009) Minireview: Obesity and breast cancer: the estrogen connection. Endocrinology 150 (6):2537-2542

19. Cleary MP, Grossmann ME, Ray A Effect of obesity on breast cancer development.

Veterinary pathology 47 (2):202-213

20. Gonzalez CA, Riboli E Diet and cancer prevention: Contributions from the European

Prospective Investigation into Cancer and Nutrition (EPIC) study. Eur J Cancer 46 (14):2555-

2562

21. Rose DP, Vona-Davis L Interaction between menopausal status and obesity in affecting breast cancer risk. Maturitas 66 (1):33-38

22. Sieri S, Krogh V, Ferrari P, Berrino F, Pala V, Thiebaut AC, Tjonneland A, Olsen A, Overvad K, Jakobsen MU, Clavel-Chapelon F, Chajes V, Boutron-Ruault MC, Kaaks R, Linseisen J, Boeing H, Nothlings U, Trichopoulou A, Naska A, Lagiou P, Panico S, Palli D, Vineis P, Tumino R, Lund E, Kumle M, Skeie G, Gonzalez CA, Ardanaz E, Amiano P, Tormo MJ, Martinez-Garcia C, Quiros JR, Berglund G, Gullberg B, Hallmans G, Lenner P, Bueno-de-Mesquita HB, van Duijnhoven FJ, Peeters PH, van Gils CH, Key TJ, Crowe FL, Bingham S, Khaw KT, Rinaldi S, Slimani N, Jenab M, Norat T, Riboli E (2008) Dietary fat and breast cancer risk in the European Prospective Investigation into Cancer and Nutrition.

Am J Clin Nutr 88 (5):1304-1312

23. Hudes GR (2007) mTOR as a target for therapy of renal cancer. Clin Adv Hematol Oncol 5 (10):772-774

24. Rubio-Viqueira B, Hidalgo M (2006) Targeting mTOR for cancer treatment. Curr Opin Investig Drugs 7 (6):501-512

25. Motoshima H, Goldstein BJ, Igata M, Araki E (2006) AMPK and cell proliferation-AMPK as a therapeutic target for atherosclerosis and cancer. The Journal of physiology 574 (Pt 1):63-71

26. Igata M, Motoshima H, Tsuruzoe K, Kojima K, Matsumura T, Kondo T, Taguchi T, Nakamaru K, Yano M, Kukidome D, Matsumoto K, Toyonaga T, Asano T, Nishikawa T, Araki E (2005) Adenosine monophosphate-activated protein kinase suppresses vascular smooth muscle cell proliferation through the inhibition of cell cycle progression. Circulation research 97 (8):837-844

27. Jones RG, Plas DR, Kubek S, Buzzai M, Mu J, Xu Y, Birnbaum MJ, Thompson CB (2005) AMP-activated protein kinase induces a p53-dependent metabolic checkpoint. Mol Cell 18 (3):283-293

28. Imamura K, Ogura T, Kishimoto A, Kaminishi M, Esumi H (2001) Cell cycle regulation via 553 phosphorylation by a 5'-AMP activated protein kinase activator, 5-aminoimidazole- 4carboxamide-1-beta-D-ribofuranoside, in a human hepatocellular carcinoma cell line.

Biochem Biophys Res Commun 287 (2):562-567

29. Riboli E, Hunt KJ, Slimani N, Ferrari P, Norat T, Fahey M, Charrondiere UR, Hemon B, Casagrande C, Vignat J, Overvad K, Tjonneland A, Clavel-Chapelon F, Thiebaut A, Wahrendorf J, Boeing H, Trichopoulos D, Trichopoulou A, Vineis P, Palli D, Bueno-DeMesquita HB, Peeters PH, Lund E, Engeset D, Gonzalez CA, Barricarte A, Berglund G, Hallmans G, Day NE, Key TJ, Kaaks R, Saracci R (2002) European Prospective Investigation into Cancer and Nutrition (EPIC): study populations and data collection. Public Health Nutr 5 (6B):1113-1124. doi:10.1079/PHN2002394

S1368980002001350 [pii] 
30. Carlson CS, Eberle MA, Rieder MJ, Yi Q, Kruglyak L, Nickerson DA (2004) Selecting a maximally informative set of single-nucleotide polymorphisms for association analyses using linkage disequilibrium. American journal of human genetics 74 (1):106-120

31. de Bakker PI, Yelensky R, Pe'er I, Gabriel SB, Daly MJ, Altshuler D (2005) Efficiency

and power in genetic association studies. Nat Genet 37 (11):1217-1223. doi:ng1669 [pii]

$10.1038 /$ ng1669

32. Jurinke C, van den Boom D, Cantor CR, Koster H (2001) Automated genotyping using the DNA MassArray technology. Methods in molecular biology (Clifton, NJ 170:103-116 33. Little J, Higgins JP, Ioannidis JP, Moher D, Gagnon F, von Elm E, Khoury MJ, Cohen B, Davey-Smith G, Grimshaw J, Scheet P, Gwinn M, Williamson RE, Zou GY, Hutchings K, Johnson CY, Tait V, Wiens M, Golding J, van Duijn C, McLaughlin J, Paterson A, Wells G, Fortier I, Freedman M, Zecevic M, King R, Infante-Rivard C, Stewart A, Birkett N (2009) STrengthening the REporting of Genetic Association studies (STREGA)--an extension of the STROBE statement. European journal of clinical investigation 39 (4):247-266

34. Hardie DG (2005) New roles for the LKB1-->AMPK pathway. Current opinion in cell biology 17 (2):167-173

35. Luo Z, Saha AK, Xiang X, Ruderman NB (2005) AMPK, the metabolic syndrome and cancer. Trends in pharmacological sciences 26 (2):69-76

36. Brown KA, Hunger NI, Docanto M, Simpson ER Metformin inhibits aromatase expression in human breast adipose stromal cells via stimulation of AMP-activated protein kinase. Breast cancer research and treatment 123 (2):591-596

37. Gonzalez-Angulo AM, Meric-Bernstam F Metformin: a therapeutic opportunity in breast cancer. Clin Cancer Res 16 (6):1695-1700

38. Fortunati N, Catalano MG, Boccuzzi G, Frairia R Sex Hormone-Binding Globulin (SHBG), estradiol and breast cancer. Molecular and cellular endocrinology 316 (1):86-92 39. Jerry DJ, Dunphy KA, Hagen MJ Estrogens, regulation of p53 and breast cancer risk: a balancing act. Cell Mol Life Sci

40. Mantovani A, Marchesi F, Porta C, Sica A, Allavena P (2007) Inflammation and cancer: breast cancer as a prototype. Breast (Edinburgh, Scotland) 16 Suppl 2:S27-33 